\title{
Latent inhibition in the autoshaping paradigm
}

\author{
DANIEL K. TRANBERG and MARK RILLING \\ Michigan State University, East Lansing, Michigan 48824
}

\begin{abstract}
Latent inhibition was assessed in the acquisition of autoshaping in the pigeon. One group of pigeons was preexposed to an 8-sec key-light stimulus presented 50 times per session for a minimum of 10 sessions. A different group was preexposed to the experimental chamber without any scheduled events. Over 4 days of testing, the pigeons preexposed to the to-beconditional stimulus required a greater number of trials to the first keypeck, pecked after fewer trials, and pecked at a slower rate than the group not preexposed to the to-be-conditional stimulus. All these effects were statistically significant. Thus, the phenomenon of latent inhibition was extended to the pigeon and the autoshaping task.
\end{abstract}

Latent inhibition is the retardation in the acquisition of a conditional response (CR) produced by preexposure to the to-be-conditional stimulus (CS) (Lubow \& Moore, 1959). The review of the latent inhibition literature by Lubow (1973) indicates that the phenomenon has considerable generality across conditioning tasks and has been demonstrated in a wide range of species, including humans.

The purpose of this experiment was to determine whether preexposure to a to-be-CS retards autoshaping in the pigeon. In an autoshaping situation, a briefly presented key light is paired with food presentation (Brown \& Jenkins, 1968). Eventually, pigeons come to peck the key while it is illuminated. Woodruff and Williams (1976) consider autoshaping an associative learning process in which the $\mathrm{CR}$ of pecking the key is a preparatory response for the consummatory response of eating. They emphasized the high degree of biological preorganization of the $\mathrm{CR}$ as one of the factors controlling associative learning in this paradigm. Data are not available on the question of whether latent inhibition occurs in biologically preorganized systems represented by the autoshaping paradigm.

A study by Mackintosh (1973) failed to obtain latent inhibition in the pigeon in an autoshaping paradigm. Mackintosh exposed four groups of pigeons to different treatments preceding autoshaping: CS only, food only, random presentations of CS and food, and a control group that was preexposed to the background stimuli of the apparatus without any scheduled events. Although the CS-only group pecked somewhat slower than the control group over the first 2 days of autoshaping, over the entire 8 days of autoshaping, only the group exposed to random presentations of CS and food differed in the rate of keypecking from the other groups, each of which did not differ from each other.

We would like to thank Jay Strong for his assistance in running animals. Requests for reprints should be sent to D. K. Tranberg, Department of Psychology, Michigan State University, East Lansing, Michigan 48824.
Wasserman and Molina (1975, Experiment 2) also failed to obtain a latent inhibition effect when pigeons were preexposed to a to-be-CS and subsequently autoshaped to a key on which both the preexposed and a novel stimulus were presented.

It is unclear why a variety of species under a variety of testing situations show a latent inhibition effect, but a pigeon under an autoshaping procedure does not. An analysis of Mackintosh's (1973) data and Wasserman and Molina's (1975) data shows that in each case a trend in the direction of a latent inhibition effect was obtained. It may be that in these studies there was an inappropriate selection of at least one of the following four variables: (1) number of preexposures to the to-be-CS, (2) duration of intertrial interval (ITI), (3) dependent variables, and/or (4) number of subjects.

Lubow (1973) reported that, typically, 16-20 preexposures to the to-be-CS is sufficient to result in latent inhibition. Over a period of 4 days, Mackintosh (1973) preexposed his pigeons to 160 5-sec CS presentations, whereas Wasserman and Molina (1975), over a period of 7 days, preexposed their pigeons to 126 8-sec key-light presentations. It would appear, therefore, that sufficient numbers of preexposures were used in these studies. Due, however, to the biological preorganization of a pigeon's keypeck in the presence of food (Woodruff \& Williams, 1976), a substantially greater number of preexposures may be required to detect the phenomenon in pigeons.

According to Lubow and his colleagues' conditioned attention theory of latent inhibition phenomena (Lubow, Alek, \& Arzy, 1975; Lubow, Schnur, \& Rifkin, 1976), any manipulation that increases conditionability should, if applied to the preexposure phase, increase latent inhibition. Duration of ITI is a potent variable that affects acquisition of autoshaped pecking in the pigeon. Terrace, Gibbon, Farrell, and Baldock (1975) exposed 12 groups of pigeons to mean ITIs ranging from 5 to $400 \mathrm{sec}$. Median trials to first peck at a 10 -sec key light decreased as a function of an increase in the ITI. In a more recent study, Gibbon, Baldock, Locurto, 
Gold, and Terrace (1977) showed acquisition of autoshaping was a function of the ratio between intertrial and trial durations. Larger ratios resulted in faster acquisition. Mackintosh (1973) and Wasserman and Molina (1975) used ITIs of 1 min or less during both preexposure and conditioning phases. Longer ITIs may be more sensitive in detecting a latent inhibition effect (Lantz, 1973).

Selection of an appropriate dependent variable may also affect whether latent inhibition is detected in pigeons using an autoshaping paradigm. Mackintosh (1973) described behavior in terms of rate of response as a function of days of training. In order to describe acquisition of a conditional response, a more molecular analysis may be appropriate. In the autoshaping situation, trials to criterion (e.g., five consecutive trials with a keypeck) (Tomie, 1976) is a sensitive measure of acquisition.

Mackintosh (1973) used eight pigeons per group in his investigation on latent inhibition and reported that "significant differences were hard to find owing to the amount of variability in the data" (p. 85). In a within-subjects design, Wasserman and Molina (1975) preexposed four birds to a key-light stimulưs and a novel stimulus on the same response key. Under these conditions, two out of four birds pecked overall on a greater proportion of the novel stimulus trials and the group mean to peck on two trials was slightly lower for the novel stimulus. Perhaps if more subjects were used in both a between- and a within-subjects design or two-key autoshaping trials were used in a within-subjects design, the chances of obtaining a latent inhibition effect in the pigeon would be enhanced.

The purpose of the present experiment was to determine if preexposure of the CS retarded the acquisition of autoshaping in the pigeon. One group of pigeons, the stimulus-old/environment-old group $\left(\mathrm{S}_{\mathrm{o}} \mathrm{E}_{\mathrm{o}}\right)$, was preexposed to a minimum of 10 days with 50 to-be-CS presentations per day (mean ITI equaled $90 \mathrm{sec})$. A stimulus-new/environment-old $\left(\mathrm{S}_{\mathrm{n}} \mathrm{E}_{\mathrm{o}}\right)$ group was treated in a similar manner, only the to-be-CS was never presented during the preexposure phase. In subsequent autoshaping sessions, number of trials to the first CS keypeck was measured. This experiment differed from previous attempts to show latent inhibition in the pigeon with the use of autoshaping by (1) increasing the number of preexposures, (2) increasing the mean duration of the ITI, (3) selection of a more sensitive dependent variable, and (4) increasing the number of subjects.

\section{METHOD}

\section{Subjects}

The subjects were 24 experimentally naive adult White Carneaux pigeons maintained at $80 \%$ of their free-feeding weights. Pigeons were individually housed in a temperaturecontrolled and constantly illuminated colony room with continuous access to grit and water.

\section{Apparatus}

The experimental space consisted of a standard two-key operant conditioning chamber for pigeons manufactured by Lehigh Valley Electronics. Inside dimensions were $31 \times 35 \times 35 \mathrm{~cm}$. The intelligence panel consisted of a houselight, speaker grill, and two response keys centered above and to the left and right of a food magazine opening. Only the right, $2.5-\mathrm{cm}$ response $\mathrm{key}$, which required a minimum force of $15 \mathrm{~g}(.15 \mathrm{~N})$ for activation, was used. The key could be transilluminated with a green light by means of an IEE projector (Model 00010-01-C393-44). The key-light and houselight bulbs were GE 757 lamps and the magazine light was a Sylvania 48ESB. The houselight was positioned to direct illumination toward the ceiling. An exhaust fan, located on the rear of the chamber, provided ventilation and partially masked extraneous noises. Experimental events were controlled by standard electromechanical programming equipment located in an adjacent room.

\section{Procedure}

Pigeons were randomly assigned to either the $\mathrm{S}_{\mathrm{o}} \mathrm{E}_{\mathbf{o}}$ group or the $\mathrm{S}_{\mathbf{n}} \mathrm{E}_{\mathbf{o}}$ group.

During magazine training, pigeons were trained to approach and eat mixed grain from the food tray. Birds were individually placed into the lighted test chamber with the food hopper elevated, lighted, and filled to the brim with mixed grain. After a pigeon had eaten for about $30 \mathrm{sec}$, the hopper was lowered. Thereafter, the food hopper was elevated at irregular intervals and remained in the up position until the pigeon broke a photocell beam by inserting its head into the magazine opening. The tray lowered $3.5 \mathrm{sec}$ after the beam was broken. Magazine training continued for 30 food presentations.

Two days following magazine training, the preexposure phase began. The $S_{0} E_{o}$ group was exposed to the experimental chamber for 50 stimulus preexposure trials per session for at least 10 consecutive days. The stimulus consisted of an 8-sec illumination of the green key light and was programmed to occur according to a constant probability, variable-time 90 -sec tape (Catania \& Reynolds, 1968). The $S_{n} E_{o}$ group was also placed into the experimental chamber for at least 10 consecutive sessions and for equivalent amounts of time per session, but the green stimulus was not presented. The length of the session was determined by the time required to present 50 stimuli, approximately $80 \mathrm{~min}$. During the preexposure phase, the operant rate of pecking the right key was determined. Test sessions did not begin until a bird's operant rate of pecking was zero for 2 consecutive days.

During testing, the interstimulus interval (ISI) was $8 \mathrm{sec}$, the duration of the green key-light conditional stimulus was $8 \mathrm{sec}$, and the ITI was programmed by the variable-time 90 -sec tape. The unconditional stimulus (UCS) consisted of 3.5-sec access to mixed grain. Sessions consisted of 50 CS-UCS pairing.

The first autoshaping test session for both groups began immediately following their last preexposure session. When the last preexposure trial timed out, the autoshaping session began.

Testing continued for four 50-trial sessions. Keypecks occurring during the CS and during the ITI in each trial were recorded. The dependent measure of primary interest was the number of trials to the first CS keypeck.

\section{RESULTS}

\section{Preexposure Phase}

Groups did not differ in the number of sessions required to reach the criterion of at least 10 consecutive days of preexposure with a zero operant rate of keypecking during the final two sessions. The $\mathrm{S}_{\mathrm{o}} \mathrm{E}_{\mathrm{o}}$ group required a mean of 10.4 sessions (range: 10-12) 
of preexposure, whereas the $\mathrm{S}_{\mathrm{n}} \mathrm{E}_{\mathrm{o}}$ group required 11.4 sessions (range: 10-16) $[\mathrm{t}(22)=1.7, \mathrm{p}>.05]$. Mean number of keypecks per preexposure session between groups did not differ either. The $S_{0} E_{o}$ group engaged in a mean of .9 keypecks/session (range: 0-3.8), whereas the $S_{n} E_{o}$ group emitted a mean of 1.7 keypecks/session (range: $0-8.4) \quad[\mathrm{t}(22)=1.1$, $\mathrm{p}>.10]$.

\section{Autoshaping Phase}

Figure 1 shows the number of trials required by each bird in both groups before the first CS keypeck was engaged in. As is evident in Figure 1, the $S_{0} E_{o}$ group required a greater number of trials to make its first response. Mean number of trials to first peck for the $S_{o} E_{o}$ and the $S_{n} E_{o}$ groups, respectively, were 25.2 and 5.2. Due to unequal sample variances $[\mathrm{F}(11,11)=5.3$, $p<.01]$, degrees of freedom were adjusted before these data were statistically analyzed. The difference between groups in trials to first keypeck was significant $[\mathrm{t}(15)=4.8, \mathrm{p}<.001]$.

The mean percentage of trials with a CS keypeck for each group over blocks of 10 trials throughout the 4 days of autoshaping is shown in Figure 2. A groups by trials analysis of variance was conducted on these data. This analysis revealed a significant Groups by Trials interaction $[F(19,418)=2.28, p<.01]$. An analysis of simple main effects showed that, for the most part, the $S_{n} E_{o}$ group pecked in significantly more trials than the $S_{0} E_{o}$ group over each of the first five blocks of 10 trials (i.e., the first day of autoshaping). [For Blocks 1-5, respectively, $F(1,60)=7.5, p<.01 ; \quad F(1,60)=21.5$, $\mathrm{p}<.001 ; \quad \mathrm{F}(1,60)=8.7, \quad \mathrm{p}<.005 ; \quad \mathrm{F}(1,60)=7.9$, $\mathrm{p}<.01$; and $\mathrm{F}(1,60)=7.1, \mathrm{p}<.025$.] The only other blocks where there was a significant difference between groups were Block $7[\mathrm{~F}(1,60)=4.8, \mathrm{p}<.05]$ and Block $13[\mathrm{~F}(1,60)=4.5, \mathrm{p}<.05]$.

Figure 3 shows the mean rate of CS keypecks for both groups over blocks of 10 trials. A groups by trials

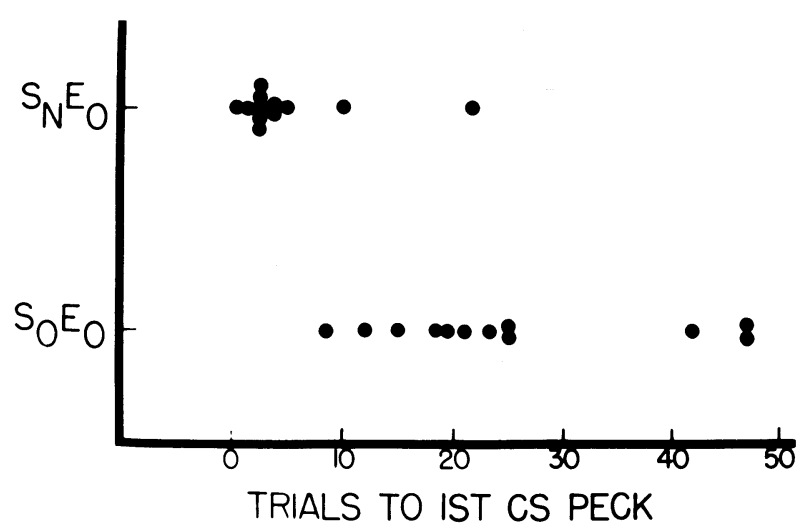

Figure 1. Number of trials required by each bird in both groups to engage in their first conditional stimulus keypeck. $S_{n} E_{o}$ refers to the stimulus-new/environment-old group; $S_{0} E_{o}$ refers to the stimulus-old/environment-old group.

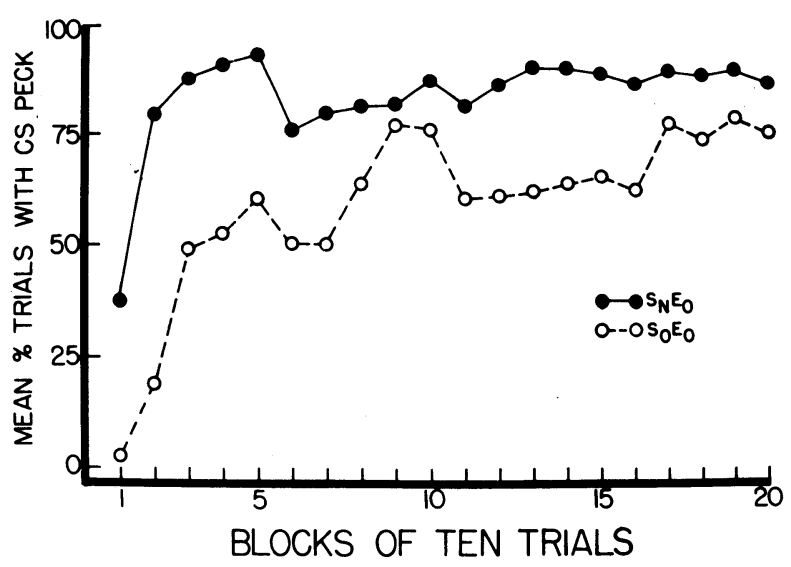

Figure 2. Mean percentage of trials with at least one conditional stimulus keypeck as a function of blocks of 10 trials for both the $S_{o} E_{o}$ and the $S_{n} E_{o}$ groups.

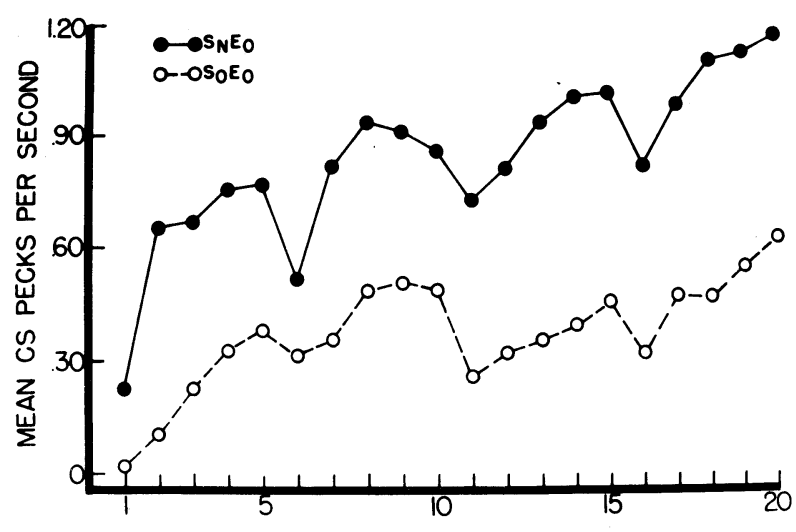

BLOCKS OF TEN TRIALS

Figure 3. Mean rate of pecking during the 8 -sec conditional stimulus as a function of blocks of 10 trials for both the $S_{0} E_{o}$ and the $S_{n} E_{o}$ groups.

analysis of variance indicated a significant effect for both CS preexposure $[\mathrm{F}(1,22)=6.5, \mathrm{p}<.025]$ and trials $[F(19,418)=9.9, p<.001]$. As indicated in Figure 3, therefore, both groups pecked at a higher rate as autoshaping continued, but the $S_{n} E_{o}$ group maintained a higher overall rate of pecking than did the $\mathrm{S}_{\mathrm{o}} \mathrm{E}_{\mathrm{o}}$ group.

The finding that the $S_{n} E_{o}$ group responded at a higher rate than the $S_{0} E_{o}$ group may be accounted for, at least in part, by the finding that the $S_{n} E_{o}$ group pecked in more trials than the $S_{0} E_{o}$ group (see Figure 2). A subsequent analysis of variance was conducted controlling for this possibility, using keypecks/trials with a keypeck as the dependent measure. The effects of CS preexposure $[F(1,22)=6.8, p<.025]$ and of trials $[F(19,418)=8.9, p<.001]$ remain significant when this is taken into account. These data indicate that the $S_{n} E_{o}$ group responded, when in fact it did respond, at a higher rate than the $S_{o} E_{o}$ group responded, when in fact it did respond. 


\section{DISCUSSION}

The present experiment clearly demonstrated a latent inhibition effect in the pigeon using an autoshaping paradigm. A group of pigeons preexposed to the to-be-CS required a greater number of trials before the first keypeck emerged, pecked in fewer trials, and at a slower rate than a group of pigeons not preexposed to the CS. Thus, the phenomenon of latent inhibition is extended to pigeons and to the autoshaping task.

The results of this experiment disconfirm previous failures to obtain latent inhibition in the pigeon using an autoshaping task (Mackintosh, 1973; Wasserman \& Molina, 1975). This discrepancy may be explained by the judicious selection of several variables in the present experiment. Past failures and current theory suggested that: (1) to reduce the problem of variability in the acquisition of autoshaping (Mackintosh, 1973), large numbers of subjects should be used; (2) conditioned attention theory suggested that any manipulation that increases conditionability should, if applied to the preexposure phase, increase latent inhibition (Lubow et al., 1975; Lubow et al., 1976). Since longer ITIs result in more rapid autoshaping (Terrace et al., 1975), the mean ITI was substantially increased in the present experiment. It does not appear, however, that the selection of a more sensitive dependent variable was critical in obtaining the present effect. Not only did groups differ in trials to first response, they also differed in percentage of trials with pecking and in rate of pecking.

The final variable changed in this experiment was an increased number of stimulus preexposures. It is not clear whether the increased number of stimulus preexposures per se had an effect on the group differences obtained or if the criterion of two successive sessions with a zero rate of operant pecking played a role. Although somewhat discredited (see Lubow, 1973), the extinction of the orienting response hypothesis suggested to us that the birds should not be pecking at the stimulus immediately prior to the autoshaping trials. The orienting response hypothesis states that for conditioning to proceed the CS must elicit an orienting response (Sokolov, 1963). Translated to the phenomenon of latent inhibition, this implies that for a latent inhibition effect to be obtained, the orienting response should be effectively extinguished. Thus, in order to extinguish the orienting response to the key light, we felt a large number of preexposures to the stimulus with the stipulation of zero rate of operant pecking was justified.

An interesting problem for future work is to determine if, in the present experiment, autoshaping was actually slowed down in the $S_{o} E_{o}$ group or if autoshaping was facilitated in the $\mathrm{S}_{\mathbf{n}} \mathrm{E}_{\mathrm{o}}$ group. Comparing the data of this experiment to that of Terrace et al. (1975), it appears that the $S_{o} E_{o}$ group initially pecked after a number of trials similar to naive pigeons in the Terrace et al. study. In the present experiment, a 90-sec ITI with an 8-sec CS resulted, after a minimum 500 to-be-CS preexposures, in an autoshaped peck after a mean of 25.2 trials. Extrapolating from the Terrace et al. data, a 90-sec ITI and a 10-sec CS resulted in pecking after 25 trials. In contrast, the $\mathrm{S}_{\mathrm{n}} \mathrm{E}_{\mathrm{o}}$ group pecked after only 5.2 trials. It may be, therefore, that extensive habituation to chamber cues facilitates conditioning, whereas preexposure to a to-be-CS cancels out this facilitative effect.

\section{REFERENCES}

Brown, P. L., \& Jenkins, H. M. Autoshaping of the pigeons' keypeck. Journal of the Experimental Analysis of Behavior, 1968, 11, 1-8.

Catania, A. C., \& Reynolds, G. S. A quantitative analysis of the responding maintained by interval schedules of reinforcement. Journal of the Experimental Analysis of Behavior, $1968,11,327-383$.

Gibbon, J., Baldock, M. D., Locurto, C., Gold, L., \& TERRACE, H. S. Trial and intertrial durations in autoshaping. Journal of Experimental Psychology: Animal Behavior Processes, 1977, 3, 264-284.

LANTZ, A. E. Effect of number of trials, inter-stimulus interval, and disinhibition during CS habituation on subsequent conditioning in CER paradigm. Animal Learning \& Behavior, 1973, 1, 273-277.

Lubow, R. E. Latent inhibition. Psychological Bulletin, 1973, 79, 398-407.

Lubow, R. E., Alek, M., \& ARzy, J. Behavioral decrement following stimulus preexposure: Effects of number of preexposures, presence of a second stimulus, and interstimulus interval in children and adults. Journal of Experimental Psychology: Animal Behavior Processes, 1975, 1, 178-188.

Lubow, R. E., \& Moore, A. U. Latent inhibition: The effect of non-reinforced preexposure to the conditional stimulus. Journal of Comparative and Physiological Psychology, 1959, 52, 415-419.

Lubow, R. E., SchnuR, P., \& Rifkin, B. Latent inhibition and conditioned attention theory. Journal of Experimental Psychology: Animal Behavior Processes, 1976, 2, 163-174.

Mackintosh, N. J. Stimulus selection: Learning to ignore stimuli that predict no change in reinforcement. In R. A. Hinde \& J. Stevenson-Hinde (Eds.), Constraints on learning: Limitations and predispositions. New York: Academic Press, 1973.

Sokolov, Y. N. Perception and the conditioned reflex. New York: Pergamon Press, 1963.

Terrace, H. S., Gibbon, J., Farrell, L., \& Baldock, M. D. Temporal factors influencing the acquisition and maintenance of an autoshaped keypeck. Animal Learning \& Behavior, 1975, 3, 53-62.

ToмIE, A. Interference with autoshaping by prior context conditioning. Journal of Experimental Psychology: Animal Behavior Processes, 1976, 2, 323-334.

Wasserman, E. A., \& Molina, E. J. Explicitly unpaired keylight and food presentations: Interference with subsequent autoshaped keypecking in pigeons. Journal of Experimental Psychology: Animal Behavior Processes, 1975, 1, 30-38.

Woodruff, G., \& Williams, D. R. The associative relations underlying autoshaping in the pigeon. Journal of the Experimental Analysis of Behavior, 1976, 11, 1-8.

(Received for publication December 27, 1977.) 